\title{
Biology and Philosophy V. Intermission. Goethe as an Appetizer
}

\author{
Juan S. Gómez-Jeria
}

\begin{abstract}
I comment on my proposition that certain parts of Faust I relate fragments of Goethe's internal search. First I comment about language as a tool for group exchange of information. Inner speech (thinking with words) is a new and a potent tool to develop an inner personal world whose wealth and complexity are related to the number of words that the individual handles. Some people expose part or all of their inner worlds through books, theater plays, speeches, etc. Internal and external languages serve to formulate what I consider a fundamental question: During my life have I done anything different from what a chimpanzee does? Goethe was a prolific writer but he had never before written about philosophy. Examining Faust $I$ you find clear signs of internal dissatisfaction coupled with a lack of ability to climb to the higher echelons of the human mode. This failure is confessed when Faust makes an arrangement with Mephistopheles and seduces a teenage girl. Faust returns to one of the main biological impulses, and a strong one: sex. Faust/Goethe is totally dominated by the soul that grips the earth with all its senses, as he says. No philosophy is possible now.
\end{abstract}

Index Terms-Genetics, human evolution, biology, chimpanzees, Goethe, language, Faust, Mephistopheles.

It is not enough to don a white coat and say, "I am a scientist". Nobody can say "I am a musician" if he buys a plectrum and a cithara; nor "I am a smith" if he puts on a felt cap and an apron; but the guise fits the art, and they get their name from the art, not from the guise. But in many cases this happens (modified from Epictetus, Discourses, IV, 8, 15). He, who can read, let him do so.

\section{INTRODUCTION}

I have decided to present in this text some thoughts on the relationship between biology and philosophy before continuing with some of the Greek philosophers ${ }^{1-4}$. The main reason is that I think it is a priority to try to show where I am going and what the limitations of this path seem to be. I will comment on some problems with language and I will present Goethe as an example of, to put it in some way, 'philosophical impotence'.

\section{LANGUAGE AND SOME OF ITS PROBLEMS}

With all the restrictions of our current knowledge of the subject of human evolution, it is possible today to write down a long and provisional list of ancestors and close relatives: Sahelanthropus tchadensis, Orrorin tugenensis, Ardipithecus ramidus, Ardipithecus kadabba, Australopithecus afarensis, Kenyanthropus platyops, Australopithecus garhi, Homo habilis, Homo erectus, Homo naledi, Homo rudolfensis, Homo antecessor, Neanderthals, Denisovans, Homo

Juan S. Gómez-Jeria, Faculty of Sciences, University/ of Chile. Santiago, Chile heidelbergensis, anatomically modern Homo sapiens, Homo sapiens idaltu, Homo floresiensis, today's Homo sapiens, etc. I suppose that all readers will easily admit that we are Homo sapiens, but I am not sure if we are all human beings (if the concepts 'Homo sapiens' and 'human being' were synonyms, one of them would probably be unnecessary). Now, as members of the genus Homo and the taxonomic order Primates, we have a series of behaviors associated with that membership.

Probably the most important of all our features is language. There is a long road from the sounds that our ancestors emitted when they hunted, fought among themselves, mated, etc., to a phrase such as 'spectroscopy shows that this paper sample contains gelatin'. That is with respect to external language. Today we know of the existence of at least two different groups of Homo sapiens, one in the sub-Saharan geographical area having only DNA from its ancestors (the anatomically modern Homo sapiens) and another group having the same DNA but with Neanderthal and Denisovan and perhaps other DNA contributions. Given that presently the languages of both groups do not seem to show differences allowing two entirely different groups of languages to be defined, it is possible to accept the hypothesis that the biological structures allowing speech as we now practice it existed in Africa and that the members of the last or latest migrations out of Africa carried that capacity with them. The question that remains unanswered is what kind of vocal communication Neanderthals and Denisovans had and how they interacted before they came into contact with Homo sapiens. The ancestors of Neanderthals and Denisovans left Africa circa 650 kybp and by 450 kybp they had separated into these two lineages. The recent discovery that both groups overlapped for approximately 96,000 years in the Denisova Cave, suggests the possibility that they could intercommunicate vocally ${ }^{5,6}$. Also, it is almost clear that Neanderthals produced what can be called "cognitive artifacts and products" (cave paintings, eagle talons from the site of Krapina, etc.) before they started mating with Homo sapiens. We do not know what happened when Homo sapiens met Neanderthals ('pure' or mixed with Denisovans) and mated with them, but in the end some kind of common vocal communication should have developed ${ }^{7}$.

At these times our ancestors had to walk or run for kilometers and hunt to find food. They did not know when the next meal time would be. They ate the high calorie nutrients that augmented their chance of survival when starving. As their body (and ours) was prone to starvation, it evolved to eat everything available and to store it. Also, our ancestors were often involved in intense physical activity such as hunting for 
prey, fighting or escaping predators. Almost all, if not all, of these activities required 'vocal' interactions among the participants. To preserve the integrity of a group, there must be a 'list' of 'sounds' having the same meaning for all members. Regarding the dynamics of the Eurasian population, a simulation has shown that 'the population size declined from about 330,000 people at $30 \mathrm{ky}$ ago to a minimum of 130,000 people at $23 \mathrm{ky}$ ago. The Late Glacial population growth was fastest during Greenland interstadial 1 , and by $13 \mathrm{ky}$ ago, there were almost 410,000 people in Europe $^{, 8}$. Dennell et al. cite a figure of between 500,000 and $1,000,000$ individuals during interglacial conditions in Eurasia ${ }^{9}$. The fact is that we were very few, perhaps in groups of between 25 and 50 individuals. If, for a given moment of time, we could mark with an ' $x$ ' the geographical position of each existing group and then join all connected groups with lines we would build a web-like structure that could help us to understand how new 'sounds' (words) and material products traveled. It is clear that this kind of map is actually possible only for more recent times, restricted geographical areas and cultural products (the Venus statuettes for example). We can assume that part or all of the sets of sounds with which these groups initially interacted were maintained, especially those of daily use in the group or during interactions with other groups (this is necessary, for example, for the exchange and/or abduction of females to avoid inbreeding between closely related individuals and the increased risk of autosomal recessive disorders in the offspring). Now, the hypothesis that the form of regularly used 'words' changes at a much slower speed than less common words seems logical. This aspect of languages must have evolved gradually and in strict Darwinian style.

There must have been a time when a group hunted a mastodon and was preparing to process it when a new group arrived on the scene. That should have triggered a process of grunting and physical attitudes indicating the possession of the object and the willingness to defend it at all costs. A long time has passed and again a new group hunted a mammoth and was preparing to process it when another group arrived. That should have triggered a process of physical attitudes indicating the possession of the object and the willingness to defend it at all costs, but also a succession of connected and more complex 'sounds' that could mean 'we killed it', 'it is ours', 'do not come near', 'we will not share it', 'we will kill you' (this is an example). In summary, language has to do with communication, not with thought itself, and the local and temporal evolution of this process has produced the different natural languages ${ }^{10}$. For the moment we are not interested in this process. I think that we all know that this great evolutionary ability has many flaws. A tool that served for communication between the members of a group of for communication between different groups serves also for other purposes, such as to introduce daily lies (for example, some politicians are professional liars) or to transform one thing into its opposite. And, something that is more serious and extremely important, not all the members of a group handles the same number of words.

A separate problem is the date when inner speech ('thinking with words') was born. Today, for most of us, inner speech is simply external speech but 'occurring inside us'. Its use is so natural in most of us (I employ 'most of us' because I am not sure if all Homo sapiens have the same kind of inner speech) that it is really difficult to build a timeline for its development. Besides helping to enhance and ameliorate the above-mentioned negative aspects of external speech, this evolutionary feature allows us, for example, to analyze the possible outcomes of future actions (analyzing the future), what other alternatives we had to respond instead of the way we did (analyzing the past) and, above all, create more words when needed, create new knowledge, new ways of considering the cosmos (worldview or Weltanschauung), etc. Let's say in passing that the invention of almost all artificial languages is due to the need of a common language for certain disciplines (chemistry for example) whose terms do not possess either intensional or extensional vagueness. Considering the expression ex nihilo nihil fit (Parmenides) as a theorem, a logically correct corollary might be that people who handle less words have more problems to appreciate and analyze with their inner speech the different 'colors' and 'flavors' that the World presents to us. The limit case is that of someone who 'sees' everything in black or white (it is true that there is also the case of someone who handles many words but sees everything in black or white because he became prey to an ideology at some point in his life). And with more words, the internal world is richer. Now I am going to continue in the next section with the analysis of what I consider to be the most important question that every Homo sapiens must ask himself using his inner speech.

\section{WHAT HAVE YOU DONE?}

Allow me to present the example of chimpanzees as the basis for formulating the central question of this long search (taken from the Wikipedia in English). Chimpanzees live in large multi-male and multi-female social groups, which are called communities. Within a community, the position of an individual and the influence the individual has on others dictates a definite social hierarchy. Chimpanzees live in a hierarchy wherein more than one individual may be dominant enough to dominate other members of lower rank. Typically, a dominant male is referred to as the alpha male. The alpha male is the highest-ranking male that controls the group and maintains order during disputes. In chimpanzee society, the 'dominant male' is not necessarily the largest or strongest male but rather the most manipulative and political male that can influence the goings on within a group. Male chimpanzees typically attain dominance by cultivating allies who will support them in future grabs for power. The alpha male regularly displays by puffing his normally sleek coat up to increase his apparent size and charge to seem as threatening and as powerful as possible; this behavior serves to intimidate other members and thereby maintain power and authority, and it may be fundamental for the alpha male to hold on to his status. Lower-ranking chimpanzees will show respect by submissively gesturing in body language or reaching out their hands while grunting. Female chimpanzees will show deference to the alpha male by presenting their hindquarters. Female chimpanzees also have a hierarchy, which is influenced by the position of a female individual 
within a group. In some chimpanzee communities, young females may inherit high status from a high-ranking mother. Dominant females will also ally to dominate lower-ranking females: whereas males mainly seek dominant status for its associated mating privileges and sometimes violent domination of subordinates, females seek dominant status to acquire resources such as food, as high-ranking females often have first access to them. Both genders acquire dominant status to improve social standing within a group. Community female acceptance is necessary for alpha male status; females must ensure that their group visits places that supply them with enough food. A group of dominant females will sometimes oust an alpha male which is not to their liking and back another male, in whom they see potential for leading the group as a successful alpha male. The mating system within each community is polygynandrous, with each male and female possibly having multiple sexual partners. The reader will easily notice that if we exchange the term 'chimpanzee' for 'Homo sapiens' in the above text, we get something quite similar to our current situation. Regarding human mating we can mention that, of the 1,231 societies listed in the 1980 Ethnographic Atlas, 186 were found to be (nominally) monogamous, 453 had occasional polygyny, 588 had more frequent polygyny and 4 were polyandrous.

What is to be a chimpanzee? To be born, to feed, to play, to sleep, to grow, to learn, to live in a stable environment, to reproduce, to make war sometimes and to die, all in a 'chimpanzee way'. Interestingly, this is exactly the same as what we do.

So, the essential question that every reader should ask himself is this: During my life have I done something different from what a chimpanzee does? I will try to find some possible answers to discuss it. 'I went to school to learn what I needed for the next stage of my life. At the same time I took advantage of play'. Chimpanzees learn and play also and their parents do not need to kill themselves working to pay for the education of their offspring. 'Then I went to the University to study the career I liked. That way I could have a better personal environment in the future. That allowed me to stabilize monetarily and to buy a house, one or two cars and a summer house, get married or live with a partner, have a son and a daughter, educate them, etc. And die'. Unfortunately, chimpanzees do exactly the same thing but at a lower cost, with greater efficiency, and only to the extent that their personal genetics allow it. They do not even need to remake the bed they slept in! Their sexual life is similar to ours. This is a fundamental question that anyone should answer as earliest as possible. The other moment is mid-life, the time from ages 45-64 where an individual is often evaluating his or her own life. What have I done for myself during all this time?

If you never posed this question to yourself, shout Hallelujah! because you are the almost perfect human primate. If you are older than 55 and have never asked yourself what you have done for yourself all this time, shout Hallelujah! again because you are the perfect human primate! If this is the case, stop reading this text, erase the computer file or burn this paper, and get on with your daily life. In summary, live the life your genetics evolved for. Your best hope is to think that one of your descendants could reach the biological level on which he can ask himself such questions.

\section{WHAT CAN WE DO?}

I will hold that when someone comes, by any procedure, to ask him this question and feels compelled to search for a convincing answer, the possible outcomes are many. The first and most obvious possibility is to believe that there is no answer at all to that question because it is incorrectly formulated in the sense that our fate to be born, to reproduce and to die is all that exists. This type of response produces depression, apathy and/or suicide of a very special kind (self-euthanasia).

Other answers consist of inventing, sometimes axiomatically, prolongations of life after death, prolongations that are inhabited by almost identical copies of us that also possess all our physical senses. And here there is a plethora of 'places': Heavens, Hells, Purgatories, etc., etc.

What is it that gives different answers to the same question? The answer is that we are born equal in rights but we are not born identical. And the difference is in the DNA. And as we reach the age to exercise some right it is our biology that allows us to fully exercise it or not 11 .

It is our biology also that simultaneously allows and limits our perception and understanding of the World. After describing the Universe in terms of certain particles and fields, theoretical physicists found it necessary to introduce dark matter and dark energy as auxiliary hypotheses as provisional responses to observations that falsified the current theory (more fields and particles). Besides, in bosonic string theory space-time is 26-dimensional, in superstring theory it is 10-dimensional and in M-theory it is 11-dimensional. There is no experimental evidence favoring any of these hypotheses. Moreover, in 1952 Erwin Schrödinger introduced the multiverse, defined today as a hypothetical group of multiple universes including ours. No experimental evidence exists. Perhaps time will show us how vast the Universe or the Multiverse is. But there are two statements that I can write with confidence. The first one holds that there is no way to declare that we know the exact size and composition of the 'Universe' (or Multiverse) and that there is no more research to be done at this regard. The second statement is that we are constrained to think only on the basis of particles and fields. Nobody is surprised to know that approximately 100 trillion neutrinos pass through his body every second. Nobody is surprised when it is suggested that dark matter should exist to explain the form and movement of galaxies and the fact that many galaxies would fly apart instead of rotating. Nobody questions this because it is Science (with a capital $\mathrm{S}$ ).

But if I state that, after reaching a certain level of biological evolution, some Homo sapiens are endowed with a 'body' existing in other dimensions and that after death this 'body' 'travels' to another Universe of the Multiverse to reincarnate, I'm going to cause a little scandal in the, at first sight, quiet Academic Pool. This is not science! Prove it! This is only present-day example of the strange but interesting mixture of Physics, Taoism and hallucinogens coming together in the second part of the $20^{\text {th }}$ century $\underline{12}, \underline{13}$. But a lot of people live 
very handsomely by writing books about these topics, about daily visits of aliens and about a heap of intellectual trash transformed into serious matter by simply adding the word 'quantum' or 'science'. And the average gentleman continues to feed on this nonsense and nobody does anything to avoid it. Now I will present some short comments on the case of a particular treatment given to the abovementioned problem by a particular person: Goethe.

\section{GOETHE OR A PHILOSOPHICAL FAILURE}

It seems that Goethe was more intelligent than average. $\mathrm{He}$ wrote novels, epic and lyric poetry, prose and verse dramas, memoirs, an autobiography, literary and aesthetic criticism and treatises on botany, anatomy and color. At the beginning of this work I thought that Goethe had all the biological elements to allow him to reach other mind/body states, observing and analyzing his life and work from some completely new and fruitful vantage points, i.e., that Goethe could be considered as a philosopher. I think that his Faust, presented as a tragic play in two parts (Faust I and Faust II), is a veiled admission of his ultimate failure to do philosophy. I agree with many in that this text is Goethe's magnum opus and the greatest work of German literature $\frac{14-18}{\text {. I will }}$ comment only on Faust I (Faust hereafter). The Masonic themes appearing there will not be investigated. In accordance with what I said above, this text is based on the thesis that Faust is one of Goethe's facets. At the beginning of the opus Faust/Goethe recognizes his total failure $\frac{14}{\text { : }}$

Faust: I've studied now, to my regret,

Philosophy, Law, Medicine,

and - what is worst- Theology

from end to end with diligence.

Yet here I am, a wretched fool

and still no wiser than before.

I've become Master, and Doctor as well,

and for nearly ten years I have led

my young students a merry chase,

up, down, and every which way and

find we can't have certitude.

This is too much for heart to bear!

I well may know more than all those dullards,

those doctors, teachers, officials, and priests,

be unbothered by scruples or doubts,

and fear neither hell nor its devils but

I get no joy from anything, either,

know nothing that I think worthwhile,

and don't imagine that what I teach

could better mankind or make it godly.

Then, too, I don't have land or money,

or any splendid worldly honors.

No dog would want to linger on like this!

He recognizes that after all his studies he is not wiser than before undertaking them (he holds Master's and Doctor's degrees), and shows a deep dissatisfaction ('I get no joy from anything'). What he does not realize is the possibility that there are other ways to deal with this dissatisfaction (Buddha for example). He then decides to use another tactic:
Faust. That is why I've turned to magic, in hope that with the help of spirit-power

I might solve many mysteries,

so that I need no longer toil and sweat to speak of what I do not know, can learn what, deep within it, binds the universe together, may contemplate all seminal forces and be done with peddling empty words.

Having at hand a book by Michel de Nostredame, Faust first contemplates the sign of the Macrocosm, and still he shows his dissatisfaction:

Faust: How all things interweave as one and work and live each in the other! Lo! heavenly forces rise, descend, pass golden urns from hand to hand, crowd from on high through all the earth on pinions redolent of blessings, and fill the universe with harmony! How grand a show! But, still, alas! mere show. Infinite Nature, when can I lay hold of you and of your breasts? You fountains of all life on which the heavens and earth depend, towards which my withered heart is straining you flow, you nurse, and yet I thirst in vain!

Here Faust invokes the Spirit of the Earth and says: 'You, Spirit of the Earth, are closer'. Almost at the end of the conversation with the Spirit of the Earth, Faust has the nerve to affirm:

Faust: How close I feel to you, industrious spirit, whose strands encompass all the world!

But the Spirit of the Earth's answer is firm and clear:

Your peer is the spirit you comprehend;

mine you are not!

At this moment Faust's actions and thoughts are interrupted by the arrival of a new character: Wagner. The opinion Faust has about him is not a good one:

Faust: Damnation! I know the sound of my assistant my happiest moment is destroyed.

Why must that humdrum plodder disturb this plenitude of visions!

Wagner seems to personify 'normality' or 'mediocrity' (or both). I have found no insightful studies about him and his role in this tragedy. But, while reading a $19^{\text {th }}$ century

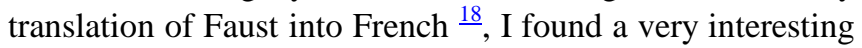
essay on Faust II written by Henri Blaze, Baron de Bury. M. de Bury, like me, does not like Wagner too much. I found in de Bury's text this appealing phrase (thanks to Bruce Cassels for the translation):

Is it not better to be Faust, standing on the Brocken, exposed to all the tempests of heaven and earth that tarnish the human soul,

than that wretched Wagner who lives happily for sixty 
years, but scorned,

and does not realize that he is a ridiculous toy of destiny?

[The Brocken is the highest peak of Northern Germany. It has always been associated with devils and witches. During the Third Reich it was declared part of a nature reserve (1937) and a conservation area (1939)].

De Bury presents Faust and Wagner as sharply opposite models or ideals to follow or imitate. But this is not correct. If we accept that all people presently living on Earth must be ascribed to one of these two models, I have no doubt that $99,999999 \%$ of the population can be catalogued as being "Wagner" in varying degrees. The question is, I repeat, that to be Faust or somebody like him you need the appropriate biology, and therefore there is no possibility of choosing to be one or the other. After a conversation, Wagner leaves the scene and Faust says:

Faust. How can a person still have any hopes who is addicted to what's superficial, who grubs with greedy hand for treasures and then is happy to discover earthworms! Is it right to let that voice be heard where inspiration compassed me about? And yet, this once you have my gratitude, you sorriest of mortals you snatched me from a desperation that threatened to destroy my mind. So gigantic was the apparition that I, alas, could only think myself a dwarf.

After an attempted suicide and during a visit to the countryside, Faust continues to complain:

Faust. Happy the man who still can hope to swim to safety in this sea of error. What we don't know is what we really need, and what we know fulfills no need at all.

Faust. Alas! it is so hard to find corporeal wings that match those of the human mind.

....

Faust. You only know one driving force, and may you never seek to know the other!

Two souls, alas! reside within my breast, and each is eager for a separation:

in throes of coarse desire, one grips

the earth with all its senses;

the other struggles from the dust

to rise to high ancestral spheres.

At that moment a black dog appears. Faust perceives it in one way and Wagner in another. Finally Faust takes him to his study cabinet. There he continues complaining but soon he realizes that the black dog is not what it seems to be. Finally, Mephistopheles appears, dressed as a goliard (a wandering student of the 12th or 13th century who wrote satirical Latin poetry):
Mephistopheles. What's all the noise? Sir, how can I be of service?

Mephistopheles acts here as Faust's servant and, in this sense he can be assimilated to a spiritus familiaris of the Liber Theysolius ${ }^{19}$. But at a certain moment he seems to be freed (or separated) in some way from Faust and, as an apparent fully separate entity, makes a deal with him. Faust's arrangement is that if he is so pleased with whatever Mephistopheles gives him that he wishes to stay in that moment forever, then he will die at that moment. In my modest opinion it is crystal clear that Goethe 'gave up' at a point of his own personal search when he wrote that the first use of Faust's power after signing a pact with Mephistopheles is to seduce a teenage girl. Dr. Faust returns to one of the main biological and strong impulses: sex. Faust/Goethe is dominated by the soul that grips the earth with all its senses (see above). And it becomes impossible to do philosophy.

To finish, let us examine the figure of a curious $19^{\text {th }}$ century wooden sculpture in the Salar Jung Museum in Hyderabad, India. One side of the statue depicts Margarete and the other side shows Mephistopheles (Credits: Nagasreenivasarao Puppala).

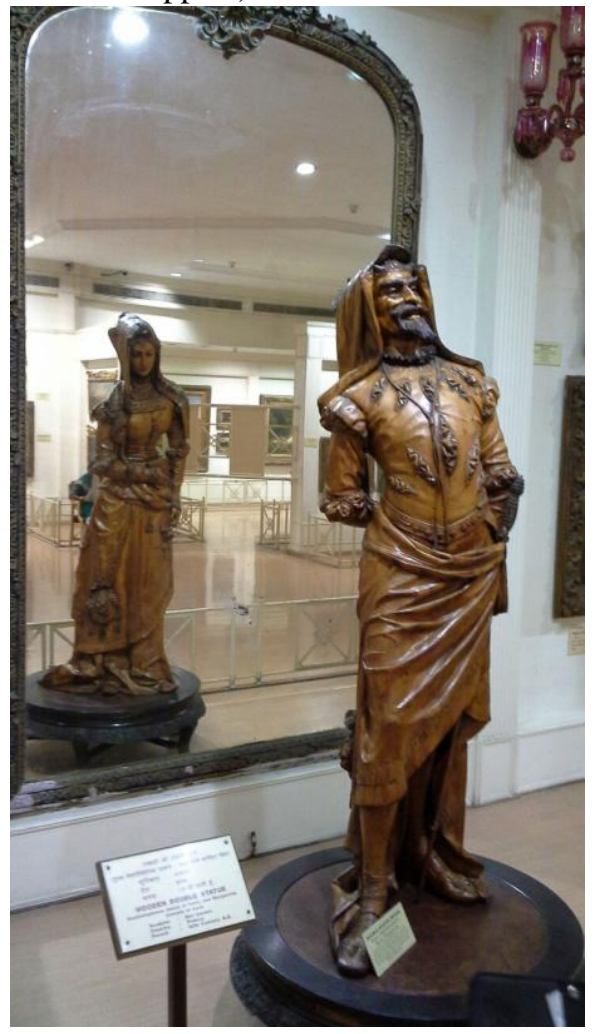

The creator of this beautiful sculpture melts Margarete with Mephistopheles. It is an excellent representation of the relationship between spirits linked to the Earth with the most basic earthly instinct of almost everyone: sex. In this extreme situation philosophy is no more possible. Perhaps for this reason Goethe never wrote on philosophy. Knowing that the stone that all the builders have rejected is the cornerstone, Europe had to wait until the last part of the $19^{\text {th }}$ century for this cornerstone: Friedrich Nietzsche. 


\section{REFERENCES}

[1] Gómez-Jeria, J. S. Biology and Philosophy IV. The Presocratics. World Journal of Research and Review 2018, 7, 44-50.

[2] Gómez-Jeria, J. S. Biology and Philosophy. III. About Mongrels and How to Shoot down a Crab from a Tree. World Journal of Research and Review 2018, 7, 1-4.

[3] Gómez-Jeria, J. S. Biology and Philosophy. Part II. The Upper Paleolithic and the Holocene. World Journal of Research and Review 2017, 4, 42-47.

[4] Gómez-Jeria, J. S. Biology and Philosophy. Part I. The Paleolithic. World Journal of Research and Review 2017, 4, 21-28.

[5] Jacobs, Z.; Li, B.; Shunkov, M. V.; Kozlikin, M. B.; Bolikhovskaya, N. S.; Agadjanian, A. K.; Uliyanov, V. A.; Vasiliev, S. K.; O’Gorman, K. Derevianko, A. P.; Roberts, R. G. Timing of archaic hominin occupation of Denisova Cave in southern Siberia. Nature 2019, 565 594-599.

[6] Douka, K.; Slon, V.; Jacobs, Z.; Ramsey, C. B.; Shunkov, M. V.; Derevianko, A. P.; Mafessoni, F.; Kozlikin, M. B.; Li, B.; Grün, R.; Comeskey, D.; Devièse, T.; Brown, S.; Viola, B.; Kinsley, L.; Buckley, M.; Meyer, M.; Roberts, R. G.; Pääbo, S.; Kelso, J.; Higham, T. Age estimates for hominin fossils and the onset of the Upper Palaeolithic at Denisova Cave. Nature 2019, 565, 640-644.

[7] Dediu, D.; Levinson, S. C. Neanderthal language revisited: not only us. Current Opinion in Behavioral Sciences 2018, 21, 49-55.

[8] Tallavaara, M.; Luoto, M.; Korhonen, N.; Järvinen, H.; Seppä, H. Human population dynamics in Europe over the Last Glacial Maximum. Proceedings of the National Academy of Sciences 2015, 112,8232 .

[9] Dennell, R. W.; Martinón-Torres, M.; Bermúdez de Castro, J. M. Hominin variability, climatic instability and population demography in Middle Pleistocene Europe. Quaternary Science Reviews 2011, 30, 1511-1524.

[10] Pagel, M.; Atkinson, Q. D.; Calude, A. S.; Meade, A. Ultraconserved words point to deep language ancestry across Eurasia. Proceedings of the National Academy of Sciences 2013, 110, 8471-8476.

[11] Plomin, R. Blueprint: How DNA makes us who we are. MIT Press: London, 2018.

[12] LeShan, L. The medium, the mystic, and the physicist: Toward a general theory of the paranormal. Viking Press: New York, 1974.

[13] Capra, F. The Tao of physics. Fontana: London, 1976.

[14] v. Goethe, J. W.; Atkins (Trans.), S. Faust I \& II. Princeton University Press: Oxford, 2014

[15] Schulte, H.; Noyes, J.; Kleber, P. Goethe's Faust: Theatre of Modernity. Cambridge University Press: 2011.

[16] v. Goethe, J. W.; Taylor (Trans.), B. Faust. Random House: New York, 1912.

[17] v. Goethe, J. W.; Swanwick (Trans.), A.; Hayward (Trans.), A.; Hedge (Ed.), F. F. Faust: a tragedy. John D. Williams: New York, 1882.

[18] v. Goethe, J. W.; Blaze (Trans.), H. Le Faust. Chapentier: Paris, 1842

[19] Raymond, J. Conversations with Angels: essays towards a history of spiritual communication, 1100-1700. Springer: 2011.

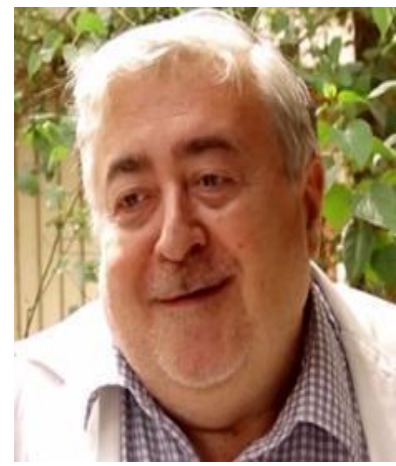

Dr. Juan Sebastián Gómez-Jeria. Graduate in Chemistry and Chemist at the University of Chile, $\mathrm{PhD}$ in Molecular Physical Chemistry (UNAB). Research in Quantitative Structure-Activity relationships, electronic structure of nanostructures and philosophy of science. Lecturer in Quantum Chemistry and Quantum Pharmacology, History and Philosophy of Science. He has published three books and more than 180 papers. 